\title{
NI REALISMO, NI ANTI-REALISMO: EL ESCEPTICISMO COMO RAÍZ DEL CONSTRUCTIVISMO FILOSÓFICO
}

\author{
NEITHER REALISM NOR ANTIREALISM:
} SCEPTICISM AS THE ROOT

\section{OF THE PHILOSOPHICAL CONSTRUCTIVISM}

\author{
RAMÓN ROMÁn AlCALÁ ${ }^{1}$ \\ Facultad de Filosofía y Letras \\ Universidad de Córdoba
}

¡Oh! este es animal que no existe. Ellos no lo sabían, pero en todo caso les agradaba su porte, su traza, su cuello, hasta la luz de su silenciosa mirada.

Ciertamente no existía. Pero, como ellos le amaban, llegó a ser un animal puro. Ellos siempre le dejaron espacio. Y en el espacio claro y libre irguió-se suavemente su cabeza y apenas necesitaba ser.

No lo alimentaron con grano, sólo siempre con la posibilidad de ser. Y esa posibilidad infundió tales fuerzas al animal,

\footnotetext{
${ }^{1}$ Departamento de Ciencias Sociales y Humanidades. E-mail: fs1roalr@uco.es
} 
que le creció en la frente un cuerno. Un cuerno. Se llegó a una doncella todo blanco... Y estuvo entonces en el argénteo espejo y en la niña.

Rainer Maria Rilke (Sonette an Orpheus)

Resumen: No cabe duda que el realismo es un problema, no es exagerado afirmar que el realismo se caracteriza de una manera diferente, dependiendo del autor que hable de él, y esto es todo un desafío para quien quiera aprender lo que es. La cuestión, pues, del realismo o del anti-realismo es una cuestión tan controvertida que un breve relato nunca va a satisfacer la discusión entre estos mismos realistas o anti-realistas. Para resolver este dilema el constructivismo propone como aspecto fundamental del conocimiento su funcionalidad. El conocimiento no se corresponde con la realidad, más bien encaja con ella o no. El realista metafísico busca el conocimiento que corresponde con la realidad, mientras que el constructivista busca encajar su teoría con lo que sabemos del mundo. El encaje describe la capacidad de la teoría, pero no del mundo. Cuando decimos de algo que "encaja" (una llave en una cerradura que la abre) ese encaja describe una capacidad de la llave y no dice nada de la cerradura.

Palabras Clave: Realismo, anti-realismo, escepticismo.

АвsтRACT: There is no doubt that realism is an issue. It is no exaggeration to say that realism is characterized in a different way depending on the author who is talking about it, and this is a challenge for anyone who wants to learn what it is. The question, then, of realism or anti-realism is such a controversial issue that a short story will never satisfy the discussion between the realists or anti-realists. To resolve this dilemma, constructivism proposes knowledge as a fundamental aspect of its functionality. Knowledge does not correspond to reality, rather it fits reality or it does not. The metaphysical realist seeks knowledge that corresponds to reality, while the constructivist seeks to fit his theory to what we know of the world. The fit describes the theory's capacity, but not the capacity of the world. When we say something that "fits" (a key in a lock that it opens), this fit describes a capacity of the key and says nothing of the lock.

KeYwORDs: Realism, antirealism, scepticism. 


\section{Introducción}

Realismo y anti-realismo aportan a la historia de la filosofía una de las discusiones más apasionantes y sugerentes de la teoría del conocimiento. El alcance y la dificultad de una controversia de estas características, lo señala el hecho de que algunos autores al hablar de estos temas, por ejemplo Wazlawick en un libro de título paradójico denominado ¿Es real la realidad?, comiencen con un principio paradójico: "lo que llamamos realidad es exclusivamente el resultado de la comunicación" ${ }^{2}$. Esta afirmación nos pone en una situación embarazosa, pues parece necesario lógicamente, antes de estudiar el tema aludido más arriba, echar una ojeada a uno de los problemas fundamentales de la filosofía: la realidad. De una manera sintética, ya que no es el tema de estudio, debemos comenzar señalando que las expresiones "es real" o "realidad" se pueden entender de cuatro maneras:

a) decir de algo "que es" o "que es una realidad", en puridad no es decir nada de "algo", es decir, no damos características de ese algo, sino que decimos que es cuantificable, o lo que es lo mismo, que es una redundancia.

b) decimos que "algo" es real cuando queremos decir que es auténtico, genuino, verdadero o natural (cuando decimos que una manzana es real, decimos que no es de cera, que se puede comer).

c) Decir que "algo" es real, también es decir que no es aparente, que no es virtual o ilusorio o que no es "Solo Posible".

d) Decir que "algo" es real o decir que es una realidad, equivale a decir que existe o que es actual, presente, es decir, la llamada realidad en este caso es equivalente a decir existencia.

Filosóficamente "es real" se ha entendido, principalmente, más en el modo c y el d, que en el a y b. En el modo c, estamos más bien ante un enfoque negativo, y en el modo d, ante un enfoque positivo. La mayor parte de los filósofos han entendido que el problema de la realidad es también el problema de cómo conocemos esa misma realidad, y la mayor originalidad de los filósofos griegos y de los sabios griegos (en el caso que nos ocupa) fue plantearse cuestiones que se podrían considerar como reflexivas, y que se clasificarían hoy en día en lo que llamamos una teoría del conocimiento.

\footnotetext{
${ }^{2}$ Watzlawick, (1979), p. 7.
} 
Este contraste entre un cierto pesimismo y un cierto optimismo epistemológico, se puede ver como el punto central de un gran debate entre el escepticismo y el dogmatismo. Y yo añadiría con una cierta actitud sesgada, lo reconozco, en un debate entre la filosofía misma como espíritu de investigación y de examen crítico, y el dogmatismo que significa que esa misma filosofía tras haber reflexionado e investigado ha conseguido establecer una doctrina bien argumentada y enseñable de manera racional.

\section{Ni realismo ni anti-realismo}

En una definición clásica e incompleta de realismo (Hessen, 1940, p. 72) se dice que entendemos por realismo "aquella posición epistemológica según la cual hay cosas reales, independientes de nuestra mente o de la consciencia”. Esta posición admite diversas modalidades, la primitiva (histórica y psicológica) es el denominado realismo ingenuo. Aquí no hay todavía influencia de ninguna teoría epistemológica, lo objetivo y lo subjetivo todavía no se hallan diferenciados, no hay pues distinción entre la percepción (como estado de conciencia) y lo percibido (como realidad ontológica). Es más, esta posición no distingue entre las cosas en su corporeidad y los contenidos de la percepción.

Diferente del realismo ingenuo, y como respuesta, surgió el realismo natural, este ya está incorporado por teorías epistemológicas que distinguen entre el contenido de la percepción y el objeto percibido. Sin embargo, sostienen que los objetos responden a los contenidos perceptivos, es decir, "la miel es dulce", se entiende todo como un paquete, y nada puede existir sólo en nuestra mente.

La tercera forma es el realismo crítico que ya descansa sobre reflexiones epistemológicas, pues no cree que todas las propiedades o cualidades de las cosas que percibimos surjan, cuando determinados estímulos externos actúan sobre nuestros órganos de los sentidos. Estas cualidades no tienen carácter objetivo, sino subjetivo, aunque hay que presuponer ciertos elementos causales en las cosas que produzcan esas cualidades y no otras.

Las tres formas de realismo se encuentran ya en el pensamiento griego antiguo. El realismo ingenuo es la posición mayoritaria de los filósofos presocráticos (a partir de Tales y Anaximandro), y que Sócrates bautizó en la biografía que 
Platón le atribuye en el Fedón, como la "investigación sobre la naturaleza"3. Este período muere en Demócrito, quien al advertir que sólo existen átomos y vacío, y las propiedades cuantitativas y cualitativas que añaden nuestros sentidos, da un salto hacia el realismo crítico (o científico como se llama hoy). A pesar de su éxito en la historia, este realismo no logró imponerse en la batalla del conocimiento, pues fue sustituido por la gran influencia de Aristóteles, por el realismo natural, ya que al contrario de Demócrito, Aristóteles defendió que las propiedades percibidas de las cosas convienen, se adecuan también a las cosas independientemente de la conciencia que las percibe o que las conoce.

No cabe duda que el realismo es un problema, no es exagerado afirmar que el realismo se caracteriza de una manera diferente, dependiendo del autor que hable de él, y esto es todo un desafío para quien quiera aprender lo que es. La cuestión, pues, del realismo o del anti-realismo es una cuestión tan controvertida que un breve relato nunca va a satisfacer la discusión entre estos mismos realistas o anti-realistas. De hecho, habría que indicar que es casi imposible hablar de realismo sin adjetivarlo para saber lo que es: realismo científico, metafísico, crítico, colorista, directo, in rebus, ingenuo, interno, escotista, moral, natural perceptual, representativo etc. Por lo que, sería imposible aceptar o rechazar el realismo en todos los campos, uno puede ser realista o anti-realista de una manera selectiva. Se podría ser realista sobre el mundo cotidiano y macroscópico y antirealista en moral o en estética.

Además, en el panorama filosófico actual, casi todos son realistas o anti-realistas: en una encuesta, muy famosa y poco convincente que circula en internet, sobre lo que creen los filósofos, sobre una muestra de 931 respuestas, aquellos que creen que el mundo consta de alguna totalidad de objetos independientes de la mente, y que la verdad es una especie de relación de correspondencia, o correlación entre palabras o signos mentales y cosas o conjuntos de cosas externas (externalistas o realistas) son el $42,7 \%$; mientras que los que creen que sólo tiene sentido preguntarse por los objetos del mundo desde dentro de una teoría o descripción son entre el 26, 4 \% (internalistas o no-realistas); mientras que los que no creen ni lo uno ni lo otro son el 30,8\%. Además, el $75,1 \%$ de los filósofos se apuntan al realismo científico, frente al 11,6\% que se apunta al antirrealismo científico, y con respecto al mundo externo un 81,6\% aceptan un

\footnotetext{
${ }^{3}$ Platón, Fedón, 97B-99B. Se necesita algo más que la experiencia de lo natural para llegar a lo verdadero, eso es lo que explica Sócrates con el deúteros plôus, segunda navegación o singladura para la búsqueda de la verdadera causa $(99 \mathrm{D})$.
} 
realismo no-escéptico, frente al 4\% que acepta un idealismo y un 9,6 \% que acepta un escepticismo).

En medio de esta catarata de optimismo realista, The Cambridge Dictionary of Philosophy (1995) (traducción Diccionario Akal de Filosofía (2004, p. 831) dice que el realismo metafísico en cualquiera de sus tres apartados (a) existen objetos reales, b) existen independientemente de nuestra experiencia o de nuestro conocimiento de los mismos, c) tienen propiedades y participan en relaciones al margen de los conceptos con los que los entendemos o del lenguaje con los que los describimos) es compartido por el sentido común, las ciencias y la mayoría de los filósofos. Como para declararse no realista. El problema está en que en el mismo diccionario y un poco más abajo dice que la principal objeción a esta posición es que no es posible formarse una concepción de los objetos reales, ya que cualquiera de estas concepciones ha de descansar en conceptos previos y en nuestro lenguaje y experiencia. Acabáramos.

Es decir, las dificultades que tienen los realistas y no digamos los anti-realistas para convencernos y demostrar sin género de duda su posición son tan acusadas que no es posible obviarlas. Además, en medio de estas deficiencias de significado, el Stanford Dictionary en su voz Scientic Realism (Abril 2011) dice que, a pesar de todas las dificultades y las diferencias en las significaciones de Realismo, se puede hablar de una receta general para el realismo que es ampliamente compartida: "nuestras mejores teorías científicas dan descripciones verdaderas o aproximadamente verdaderas de los aspectos observables y no observables de un mundo independiente de la mente". Parece que no hemos avanzado mucho desde las primeras discusiones en el pensamiento griego con los escépticos académicos que hablaban de lo razonable (eulógon) o lo verosímil (Pithanon), como criterio de verdad.

\section{La raíz del problema}

En esa definición tan vaga, está a nuestro entender el problema de fondo de la cuestión que nos propone este artículo. La cuestión no está en el realismo o no-realismo de las teorías defendidas, sino en la malla que cada teoría debe aportar a la teoría del conocimiento o al problema epistemológico de la verdad. Es decir, en la posibilidad o imposibilidad de adquirir conocimiento de la realidad, y la cuestión de si ese conocimiento es seguro o verdadero: esa es la cuestión que ocupa el pensamiento de los filósofos actuales no menos que ocupaba el pensamiento de Platón, de los estoicos o de los escépticos. Un problema 
que nos surge al ir a la raíz de la cuestión ya en el pensamiento griego, es que como advierte Putnam ${ }^{4}$, desde los presocráticos hasta Kant no ha habido ningún filósofo que de una u otra forma no haya sido un realista metafísico. Es decir, la cuestión básica no se centraba en lo que son exactamente las cosas que hay, sino en si podíamos conocer las cosas que había y cómo sabíamos que esas cosas que conocíamos eran verdad.

De todas las grandes preguntas de la filosofía griega, la primera que surge históricamente hablando tiene que ver con lo que existe, tiene que ver, evidentemente, con la física (phýsis). Y dice mejor que yo Tomás Calvo que la filosofía no surgió originalmente como "ontología", sino como "investigación sobre la naturaleza" (peri phýseos historía), siendo la noción central de esta forma de filosofar la noción de phýsis, juntamente con el verbo gígnomai (llegar a ser, generarse, devenir $)^{5}$. Sin embargo, a partir de Parménides y hasta el aristotelismo, el núcleo de las cuestiones filosóficas de carácter más universal y más problemático se configuró en el pensamiento griego como "ontología”, pues aunque el fuego, el aire o el agua (en un sentido presocrático son (éstin) todas las cosas que se generan, el agua es agua, el fuego es fuego y el aire es aire y no otra cosa. Esto quiere decir sencillamente que la reflexión sobre la realidad como tal (es decir sobre todas las cosas que se generan), sobre el lenguaje en tanto que dice o es capaz de decir o hablar sobre la realidad, y sobre la verdad como relación fundamental entre aquella y este, se plantearon finalmente desde la perspectiva del verbo 'ser' (eimí), y su participio ón/óntos en sus distintas formas y usos.

Darle vueltas aquí a "lo que es" (ón/ontos) es darle vueltas también a lo que se clasifica en el pensamiento griego como actitud complementaria "lo que es real", o "lo que es verdadero", o también más complejo "lo que es siendo lo que es". Apareciendo ya aquí, no solo la hipertrofia tradicional del verbo "ser" (de carácter ontológico) frente al más antiguo y natural uso del verbo gígnomai (llegar a ser, generarse, devenir), sino la aparición de los dos rasgos más filosóficos del verbo eimí, el de permanencia y el de presencia que tanto juego le darán a Parménides ${ }^{6}$.

\footnotetext{
${ }^{4}$ Putnam, 1988, p. 65

${ }^{5}$ Calvo advierte que conviene en principio recordar dos circunstancias de este verbo". 1. admite todos los usos que tiene el verbo eimí (absoluto existencial, "llegar a la existencia", como el uso predicativo "llegar a ser tal o cual cosa"), todo lo que puede decir el verbo eimí lo dice le verbo gígnomai, si bien este último introduce un matiz que no introduce eimi "la idea o matiz de generación o devenir. 2. En la tradición del perì physeos ambos verbos conviven pacíficamente y no hay conflicto en ellos. Cf. Calvo, 2007, p. 162.

${ }^{6}$ Cf. Calvo, 2007, pp. 162-163.
} 
De ahí, que "lo que es" (ón/ousía) se convirtió paradójicamente en el punto clave para criticar "idealmente" todos aquellos conceptos que se oponían a lo que vemos en torno a nosotros, a lo que se refiere al mundo aparente en el que se desarrolla nuestra vida cotidiana. Así frente al "ser", inmóvil, perfecto, redondo, surge el "devenir" (génesis), lo que aparece, lo que cambia y se transforma. A partir de aquí "lo que es real" y "lo que es aparente" iniciarán una batalla dialéctica en el pensamiento griego, cuyos ecos todavía perviven y siguen generando controversias (mecánica cuántica frente a realismo científico).

A pesar de la importancia que pueda tener el verbo ser, sólo una mínima tradición que comenzó por Parménides ha podido acreditar la idea que, según la sentencia escolástica, "el ser o "lo que es", es el primer objeto del intelecto" y, por tanto, debe ser el tema privilegiado de toda teorización filosófica. Aristóteles y toda la tradición doxográfica posterior asimila la propuesta parmenídea y la olvida a la vez: "En efecto, como considera que, aparte de "lo que es", no hay en absoluto "lo que no es", piensa que hay solamente una cosa, lo que es y nada más». Y también Teofrasto, citado por Simplicio, aporta el siguiente esquema: «Lo que está fuera de lo que es, es lo que no es; pero lo que no es no es nada; pues lo que es, es uno» ${ }^{8}$. De la inexistencia de lo que no es, se concluye que lo que hay es lo que es, de ahí a su unicidad, después a su unidad y por fin a su inmovilidad.

La convicción de Aristóteles y de sus comentadores de que la filosofía no puede hablar de otra cosa que de «lo que es», centraba la filosofía parmenídea en lo que no era más que un corolario (aparece sólo el v. 6 del frag. VII) el predicado de la unidad, lo cual obligó a Meliso (por razones que no vienen al caso ${ }^{9}$ ) a corregir la ontología parmenídea de la finitud. Pues, si atendemos a los sentidos, medita Meliso, sólo percibimos cosas cambiantes, movimiento continuo en un mundo de apariencias que configura un mundo contradictorio y falaz donde predomina el tránsito de lo que es a lo que no es. Por eso, la propuesta fundamental de Meliso establecerá, radicalmente, una separación tajante, no parmenídea, entre apariencia (sensible) y ser (inteligible): la pluralidad que percibimos del mundo sensible es apariencia errónea, mientras que el acto de aprehensión del ser por el pensamiento, invalida justamente ese devenir. Será, pues, la razón en su actividad la causante de la determinación de la realidad, mientras que la sensibilidad en su pasividad conduce al error. La idea del hombre como observador que percibe será sacrificada por la idea

${ }^{7}$ Aristóteles, Metaf., A 5, 986b 29.

${ }^{8}$ Simplicio, Phys., 115, 11: DK 28 A 28. Tò parà tò òn ouk ón 'tò ouk òn ouden 'Hènára tò ón,

${ }^{9}$ Román, 1993, pp. 179-193. 
del hombre que parece que constituye u organiza la realidad sin atender a los datos de los sentidos ${ }^{10}$. Y esto es lo que nos gusta señalar aquí, y tendrá sus consecuencias para el constructivismo posterior.

Siguiendo esta misma línea, Sexto Empírico cuando interpreta el Proemio de Parménides, interpreta el carro tirado por dos yeguas como el carro del alma humana, las doncellas que preceden al carro como las sensaciones (de lo cual da señas el propio Parménides al hablar de que era acelerado por dos ruedas que son los oídos, gracias a los cuales recibimos todos los sonidos), mientras que la inteligencia, la razón, sustituye en el paso de la noche a la luz a estos sentidos que se equivocan, mientras ella (la razón) aprehende las cosas con seguridad: "alcanzando la inteligencia la firme comprensión de las cosas" ${ }^{11}$. A partir de esta lectura, Sexto concluye que Parménides aconsejaba no atender a los sentidos sino a la razón: "Y en fin, él concluye claramente que no ha de atenderse a los sentidos, sino a la razón" ${ }^{12}$.

La actitud de Sexto es comprensible ya que él estaba interpretando a Parménides, quizá por influjo platónico, a través de la disyunción excluyente sentidosrazón. De tal forma que el Empírico no podía entender cómo al final del Proemio y después de calificar como "falsas" las opiniones de los mortales, éstas habrían de ser tenidas en cuenta, por lo que elimina los dos versos correspondientes introduciendo lo que a él le parece más legítimo. Esta interpretación nos llevará a la aceptación de la tradicional distinción entre el ser que representa al mundo verdadero, y la apariencia que simboliza el mundo de los fenómenos físicos erróneos. Al primero se llegaría a través del nóos, la razón, y al segundo a través de los sentidos, aisthéseis, considerando de esta forma a Parménides como el iniciador del pensamiento puro y del nóos como principio de las representaciones "puramente" intelectuales. Así, el hombre tendría dos facultades de conocimiento: el "intelecto" a través del cual llegaríamos a conocer la esencia de las cosas, y los sentidos mediante los cuales percibiríamos el mundo de los fenómenos. De aquí que se tienda, para fundamentar esta tesis, a creer que el conocimiento de lo "semejante" se tiene por lo "semejante", llegando a conocer el mundo fenoménico por los sentidos y el

\footnotetext{
${ }^{10}$ Esta idea que destaca la primacía de la razón sobre la percepción en Meliso nos parece interesante, aunque no compartimos la ampliación que hace Zafiropulos a todo el pensamiento griego, Cfr. ZAFIROPULOS, 1950, pp. 247-248, mucho menos estamos de acuerdo con el paralelismo que construye este autor entre esta actitud griega y la de Kant en la Crítica de la Razón Pura, que, según él, podía haber sido escrita por un griego del siglo $\mathrm{V}$ a. C.

${ }^{11}$ Sexto, M., VII, 113-114.

12 Sexto, M., VII, 114.
} 
mundo del pensamiento por la razón ${ }^{13}$. Con Parménides aparece, según Sexto, el primer intento de convertir a la razón en árbitro de la realidad. Esta razón tiene sus propias leyes y exigencias interiores, ya que las exteriores son todas erróneas. De la afirmación de la razón como conocedora de la realidad se deriva la negación del devenir testimoniado por la experiencia sensible. Frente al ser único, inmóvil y eterno al cual se llegará a través de la razón, los sentidos sólo serán capaces de captar el movimiento, el cambio y la multiplicidad imperfecta.

Es comprensible la exposición de Sexto con referencia al problema de la apariencia/verdad que tanto preocupó a los escépticos. Según esta interpretación, Parménides inició el ataque a los sentidos como fuente de conocimientos erróneos, en aras de una sobrevaloración de la razón ${ }^{14}$. Pero esta afirmación es una gran trampa, tal como intuirá muy pronto Demócrito: no podemos destruir el conocimiento aportado por los sentidos, ya que queramos o no es el único fundamento posible de las certezas de la razón: la desconfianza en los sentidos no tendrá más remedio que acarrear la perdición de la razón $n^{15}$. Curiosamente, la afirmación de que los sentidos jamás descubren nada sobre el "ser verdadero", es decir, sobre la esencia real de las cosas, se convertirá en uno de los argumentos más usados por los propios escépticos para negar la posibilidad de conocer la realidad, ya que si anulamos los cauces

\footnotetext{
${ }^{13}$ En el análisis de Parménides no hemos encontrado una solo ejemplo definitivo de la viabilidad de esta interpretación. No aparece, pues, en el Poema una evidencia absoluta que dé muestras de una radical posición entre conocimiento intelectivo, por un lado, y conocimiento sensitivo, por otro. Cfr. Gigon, 1944, p. 259 y Calvo, 1977, pp. 252-253.

${ }^{14}$ Es interesante observar cómo también Heráclito es interpretado de la misma forma. Según Sexto, el de Éfeso también es responsable de cierta crítica a los sentidos como fuente de conocimiento; diciendo, en este sentido, que el hombre está compuesto de dos facultades para alcanzar el conocimiento: la sensación y la razón. La sensación no es digna de confianza mientras que la razón es asumida como el criterio. Por eso, Heráclito estaría condenando la sensación cuando decía: "Malos testigos son para los hombres los ojos y los oídos cuando tienen almas bárbaras". Sexto, M., VII, 126: DK 22 B 107. Lo cual es equivalente a decir, según Sexto, que confiar en los sentidos irracionales es de almas bárbaras, Sexto, $M$., VII, 126-127. Vemos aquí como Sexto también se apresura a interpretar el texto de Heráclito acudiendo al par de contrarios: sensación "versus" razón. Recordemos aquí la crítica epicúrea a todos aquellos autores, Pirrón entre ellos, que ponen en duda la capacidad de los sentidos para el conocimiento, ya que, según Epicuro, sin los datos aportados por los sentidos no puede haber conocimiento.

${ }^{15}$ Demócrito acierta a plantear el dilema de que cualquier tipo de conocimiento racional que desconfíe del testimonio de los sentidos está condenado al fracaso. En este sentido, Galeno cita un texto de Demócrito poco tranquilizador a este respecto, en él los sentidos, maltratados, acusan amargamente a la razón de destruirlos, pero a la vez le advierten que su suerte está ligada a la de ellos: «;Oh misera razón!, ¿tomando de nosotros tus certezas (tu garantía) nos destruyes?, nuestra caída será tu perdición», Galeno, De medic. empir., 1259, 8: DK 68 B 125.
} 
a través de los cuales nos acercamos a la realidad, ésta quedará indeterminada ante la imposibilidad de su conocimiento.

En resumen, la necesidad impuesta por el sistema de Meliso de que el conocimiento verdadero sólo se obtiene a través del logos, a través de la razón demostrati$\mathrm{va}^{16}$, será uno de los argumentos más frecuentemente utilizados por los escépticos para dudar del conocimiento en general. Ciertamente, este atisbo de escepticismo eleático (al menos en lo que a los sentidos se refiere) era filosóficamente estéril, ya que era de raíz metafísica y no epistemológica, pero inició la vía en la que más tarde se reconocerán, plenamente, los mismos escépticos antiguos. Así pues, por una extraña jugada del destino los filósofos más dogmáticos inician la línea de los más antidogmáticos.

\section{La duda acerca de la correspondencia entre saber y realidad}

El escepticismo, pues, generaba una duda acerca de la correspondencia entre el saber y la realidad de la que supuestamente era referido. Se generaban dudas sobre la conexión y correspondencia de la verdad y realidad, por la imposibilidad de crear un criterio de verdad adecuado para verificar la verdad de una, con la verdad de la otra. Para Sexto, el primero que negó la existencia de un criterio como guía de la verdad, que fuese capaz de distinguir lo verdadero de lo falso con respecto a la realidad fue Jenófanes, llevando como resultado a suspender nuestros juicios sobre el conocimiento de la realidad.

Sexto Empírico hace referencia a Jenófanes en numerosas ocasiones ${ }^{17}$, en Matemáticos, VII, 49, subraya el problema de la verdad y el criterio necesario para distinguirla, y afirma que algunos pensadores han considerado que el criterio está en lo racional, otros en las evidencias no-racionales y unos terceros establecen la verdad en ambos. Sexto, no obstante, advierte que la cuestión no se

\footnotetext{
${ }^{16}$ Como ya hemos observado, en Meliso hay una rigurosa necesidad de excluir todos los valores propios de las dokoûnta, la verdad no puede provenir del examen de lo empírico, pues lo múltiple es contradictorio, cfr. Calogero, 1977, p. 95, nota 16 y las páginas mencionadas de Reinhardt, 1985, pp. 71-73.

17 Por ejemplo, en seis pasajes de sus Hipotiposis Pirrónicas, Cfr. Sexto, H.P., I, 223, 224, 225; II, 18; III, 30, 218. En otros dos del libro I de los Matemáticos: Sexto, M., I, 257, 289. En cinco del libro VII: Sexto, M., VII, 14, 48, 49, 53 y 110. En uno del libro VIII: Sexto, M., VIII, 326. En dos del libro IX: Sexto, M., IX, 193 y 361. Y, por último, en otros dos del libro X: Sexto, M., X, 313 y 314. Si bien es cierto que los pasajes no son coincidentes, pues en unos lo reconoce como a un escéptico, en lo que se refiere al conocimiento de las cosas, y, en otros como un dogmático en lo referente a su teología.
} 
circunscribe a qué criterio hay que utilizar sino más bien, si existe o puede existir ese criterio. De ahí que junto a estos autores que apuestan por un criterio, otros, entre los que destaca Jenófanes, niegan que pueda existir criterio alguno. De ahí que diga el Empírico que en lo que se refiere al criterio para Jenófanes las cosas

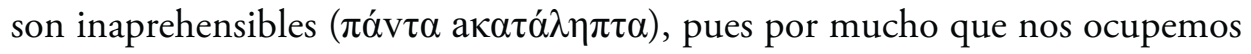
e intentemos conocer qué es la realidad nunca podremos saber si aquello que conocemos o sabemos es lo verdadero. ${ }^{18}$

En la interpretación que hace Sexto de este fragmento se observa una radical precisión al afirmar que para Jenófanes no habrá nunca un hombre que pueda conocer lo patente, o haya visto cuantas cosas digo sobre los dioses, por lo que sólo queda la opinión, la conjetura ${ }^{19}$. Me interesa destacar aquí que si algo que puede ser visto (eidòs) debe estar allí antes de que la mirada pueda posarse sobre ese algo, debe existir antes de que cualquier perceptor lo vea o lo experimente de alguna manera. Ya desde Jenófanes quedó establecido un marco conceptual o escenográfico en el que el realismo metafísico ${ }^{20}$ no era una posición epistemológica entre otras, sino la única posible. A partir de aquí la epistemología griega se deslizaba sobre raíles y sólo podía, con ayuda del escepticismo, descarrilar. Como observa Maturana (uno de los máximos representantes del constructivismo filosófico) "el supuesto a priori de que el conocimiento objetivo constituye una descripción de lo que es conocido... comete petición de principios en la preguntas ¿Qué es saber? y ¿Cómo sabemos?”

\footnotetext{
${ }^{18}$ Sexto, M., VII, 49: DK 21 B 34 [a partir de kaì tò mèn]. Este texto correspondiente a los cuatro famosos versos de Jenófanes es citado y comentado repetidamente por Sexto en tres ocasiones M., VII, 49; 110 y VIII, 326. Y la conocida frase dókos d'epi pâsi tétuktai es citada separadamente en H.P., II, 18.

19 Cfr. Fränkel, 1925, pp. 174-192. La interpretación del fragmento B 34 de Jenófanes ha tenido una historia un tanto turbulenta. Fränkel en un estudio ya clásico, intentó clarificar, a su modo, la estructura del fragmento, eliminando, por un lado, la interpretación socráticoplatónica, y por otro, el tono excesivamente escéptico que, según él, había recibido en Sexto. Ambas interpretaciones son igualmente verosímiles pero también igualmente inverificables. Siguiendo estas anotaciones de Fränkel, la estructura original del fragmento quedaría así: aquel que se acerca a lo saphés (lo patente) le falta el pleno saber sobre lo alcanzado, es decir, todavía no es un saber verdadero. No existe segura evidencia de que lo que conocemos lo

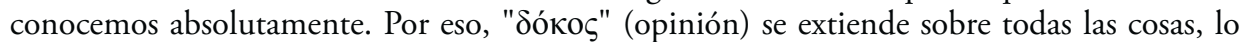
único que tenemos son sospechas, podemos estar próximos a la verdad, pero no podemos tener convicción de ese hecho, por más razones que tengamos para justificar o para creer que estamos cerca de la verdad. No se puede negar que el tono de esta interpretación de Fränkel remite también a cierto escepticismo, pues ante la imposibilidad de conocer la verdad, cualquier saber seguro se transforma en opinión dudosa.

${ }^{20}$ Por eso dice Putnam que la teoría que afirma que la verdad es una correspondencia, es la más natural y por eso es imposible hallar algún filósofo anterior a Kant que no mantuviera una teoría de la verdad-correspondencia, cf. Putnam, 1988, p. 65
} 
${ }^{21}$. Llevamos más de 25 siglos tratando de responder a esta cuestión. Y no podemos decir que en la actualidad, la mecánica cuántica, por ejemplo, haya resuelto el problema, yo diría más bien que lo ha aumentado. Pues la pregunta vigente es si podemos seguir viviendo sin necesidad de abrir la caja y saber si el gato está vivo o muerto, según la paradoja de Schrödinger.

Si damos por sentado que el conocimiento refleja o debe reflejar la realidad, la epistemología tradicional crea un dilema tan inevitable como irresoluble. Si el conocimiento ha de ser una descripción o imagen del mundo como tal, necesitamos un criterio de verdad que demuestre que nuestras imágenes o descripciones del mundo son correctas o verdaderas con respecto al mundo: el escepticismo hace su agosto por aquí. La oposición entre realidad-verdad y apariencia-error, iniciada desde Jenófanes y desarrollada por Pirrón o Sexto al hablar de la percepción, es la piedra angular de toda teoría del conocimiento. La incontestable pregunta de si, o en qué medida, toda imagen que nos transmiten nuestros sentidos puede corresponder con la realidad objetiva, tiene un amplio estudio en Sexto con el ejemplo de la manzana, que tendrá un gran éxito posterior, dice: "Así, también es posible que teniendo nosotros sólo los cinco sentidos, únicamente percibamos de las cualidades de la manzana las que somos capaces de captar; pero es posible que se den otras cualidades que caigan bajo otros tipos de sentidos de los que nosotros no estamos dotados, razón por la cual tampoco percibimos lo perceptible por ellos. ${ }^{22}$

Dicho de otra manera, por más que queramos, lo único que podemos hacer es comparar nuestras percepciones solamente con otras percepciones, pero nunca podemos comparar las percepciones con la manzana misma ${ }^{23}$. Todos estos argumentos amargaron la vida a los filósofos dogmáticos durante más de XX siglos, pero la perspectiva no mejoró con Kant, sino que empeoró, pues el creador de la Crítica añadió a este argumento de la manzana, otro más preocupante. En los Prolegómenos, Kant considera el espacio y el tiempo como aspectos de nuestra forma de experimentar, anulando, así, la posibilidad de conocer las cosas ontológicamente, y

\footnotetext{
${ }^{21}$ Maturana, 1970, p. 2

${ }^{22}$ Sexto, H.P., I, 97.

${ }^{23}$ Diógenes Laercio insiste en el mismo ejemplo al hablar de los Modos, tropos o maneras de conocer de Enesidemo y Agripa, así dice, "El tercer Modo es el que tiene que ver con los diferentes canales sensoriales; por ejemplo, una manzana a la vista es amarilla, al gusto es dulce, al olfato agradable por su aroma. Incluso las mismas formas se ven diferentes según la variedad de los espejos. De lo cual se deduce que lo que aparece no es más del modo en que aparece que de otro". D.L. IX, 81.
} 
retirándolas, por tanto, de la realidad para colocarlas en la esfera de lo fenoménico: "todo lo que puede ser dado a nuestros sentidos (a los externos en el espacio, a los internos en el tiempo) será para nosotros contemplado tal como nos aparece, no tal como es en si'”24.

Este texto no sólo pone en duda las propiedades sensoriales de la manzana, sino la propia condición de cosa de la manzana en sí, no sólo es dudoso su olor, su dulzura o su color amarillo o rojo, sino que difícilmente podemos estar seguros de que exista un objeto independientemente de cómo lo experimentamos. ¿Estaría, pues, Kant cayendo en un idealismo manifiesto? No. Kant no afirma que no haya nada fuera de mi pensamiento, como podría afirmar un idealista ostensible, es más, él confiesa que fuera de nosotros hay cuerpos, esto es, cosas que conocemos fuera de nosotros, lo que dice es que nuestra experiencia no puede enseñarnos nada sobre la naturaleza de la cosa en sí, pues conocemos sólo sus fenómenos, esto es las representaciones que producen en nosotros ${ }^{25}$. Putnam pone un ejemplo que incide en esta cuestión ${ }^{26}$ y demuestra que no existe, estrictamente hablando, un hecho objetivo (fact of the matter) respecto a los objetos del mundo, por lo que es absurdo pensar que hay una manera en que las cosas son en y por sí mismas, con independencia del esquema conceptual respectivamente elegido. Así dice, que si pensásemos que solo tenemos un mundo con tres objetos, $\mathrm{x}_{1}, \mathrm{x}_{2}, \mathrm{x}_{3}$, según nuestra noción típica de objeto habría tres objetos en el mundo, pero si fuéramos lógicos polacos que creen que la suma de los objetos es otro objeto en sí, no habría tres objetos sino siete, $\mathrm{x}_{1}, \mathrm{x}_{2}$, $\mathrm{x}_{3}, \mathrm{x}_{1}+\mathrm{x}_{2}, \mathrm{x}_{1}+\mathrm{x}_{3}, \mathrm{x}_{2}+\mathrm{x}_{3} \mathrm{y}_{1}+\mathrm{x}_{2}+\mathrm{x}_{3}$. Es decir, dependiendo de nuestro esquema conceptual cambiaría el número de objetos del mundo. Todo objetivista de los hechos, sin embargo, diría que el ejemplo de Putnam demuestra que hay numerosas descripciones del mundo, igualmente verdaderas. Aceptaría que para cualquier segmento espacio-temporal dado, puede haber varias descripciones del mismo, igualmente verdaderas, siempre que estas sean igualmente consis-

\footnotetext{
${ }^{24}$ Kant, Prolegómenos, Primera parte, \& 12.

25 "Nos son dadas cosas, como objetos de nuestra sensibilidad, existentes fuera de nosotros; pero de lo que puedan ser en sí, nada sabemos, sino que conocemos sólo sus fenómenos, esto es, las representaciones que producen en nosotros, en tanto que afectan nuestros sentidos. Según esto, confieso, ciertamente, que fuera de nosotros hay cuerpos, esto es, cosas, las cuales conocemos por medio de representaciones que nos proporcina su influjo sobre nuestra sensibilidad, aunque con respecto a lo que puedan ser en sí, nos son completamente desconocidas", Prolegómenos, Primera parte, \&, 13, Segunda observación.

${ }^{26}$ Cf. Searle, 1995, pp. 165-166.
} 
tentes $^{27}$, estando solo obligados a pensar que no toda descripción del mundo posible en un segmento espacio-temporal dado es verdadera, y que algunas serán falsas dependiendo de la correspondencia con lo que está ahí. Pero esta es la cuestión abierta si ese estar ahí es tan fácil de fijar como las descripciones verdaderas o falsas.

\section{El constructivismo filosófico}

Y aquí estamos de nuevo, desde Pirrón hasta los físicos teóricos actuales nos preguntamos cada vez con mayor frecuencia si estamos descubriendo leyes de la naturaleza o si, por la decantación fina de las teorías de investigación, estamos forzando a la naturaleza a encajar en esas hipótesis previamente concebidas. En este contexto, el escepticismo siempre ha sido un aguafiestas y un pesimista con respecto a las posibilidades del conocimiento. Y nosotros en el fondo continuamos siendo realistas metafísicos que esperamos un conocimiento que nos procure una imagen verdadera de un mundo independiente y supuestamente real, fiel a la verdad.

Como se sabe, la ciencia clásica se había propuesto como misión investigar el mundo en su realidad objetiva, independiente de lo humano. Esto significaba que para llegar a ese mundo objetivo, ese mundo sin sujeto tenía que ser alejado de toda contaminación subjetiva, por lo que debía ser distanciado también del observador. Pero el siglo XX empezó a dinamitar esta idea cuando se empezaron a multiplicar las dudas sobre la posibilidad de realizar dicho propósito. Se comenzaba a comprender que un mundo del que se había expulsado toda subjetividad era un mundo que dejaba de ser observable.

Había una interdependencia entre el observador y el mundo observado que empezó a ser el tema del discurso de teorías como el constructivismo radical. A partir de la teoría de la relatividad de Einstein, se empezó a afirmar que las observaciones son relativas al punto de referencia del observador, y el postulado de la relación borrosa o el principio de incertidumbre de Heisenberg, afirmaba que la observación influía en lo observado. El colmo llegó en 1958 con Erwin Schrödinger que aunque todavía el término constructivismo no había aparecido en el mercado de las ideas decía: "Toda imagen del mundo es y sigue siendo

${ }^{27}$ Un sistema es sintácticamente consistente cuando en él es imposible derivar una expresión determinada y también su negación (consistencia o no contradictoriedad), y es semánticamente consistente si sus expresiones admiten un modelo. 
una construcción de su propia mente; su existencia no puede ser probada de otra manera" ${ }^{28}$. Y es más contundente cuando en ese ensayo maravilloso de $L a$ naturaleza y los griegos, al hablar del orgullo y la simplicidad y temeridad de los científicos propensos, dice él, "a creer que han comprendido un fenómeno, cuando en realidad únicamente se han aprendido los hechos describiéndolos ${ }^{29}$

Einstein insistía en esto mismo cuando decía, y muchos científicos estaban de acuerdo con él, que la mente humana era activa, y que las teorías científicas eran creaciones libres de esa misma mente humana, y se asombraba de que a través de ellas (creativamente y no científicamente) pudiéramos comprender el universo. Claro, advierte Maturana, la afirmación y el asombro de Einstein surgen de la suposición implícita que tenía él mismo de que hay una realidad independiente que el observador encuentra y descifra con proposiciones explicativas, que según Einstein "surgen independientemente de toda observación directa con esa realidad objetiva" ${ }^{30}$.

Es evidente que si las suposiciones implícitas de Einstein fuesen correctas, entonces su asombro también sería correcto. El realista puede continuar dejando a un lado los argumentos escépticos, y anularlos por repugnar a un "sano" entendimiento humano, pero sigue sin resolverlos, y si los toma en serio no tendrá más remedio que retirarse a un cierto idealismo subjetivo que lleva a un inevitable solipsismo, a una cierta creencia de que no puede existir un mundo independiente del sujeto. Dicho de otro modo, el observador no encuentra un fenómeno que deba explicar fuera de él, por el contrario insiste Maturana, "el observador produce el mecanismo generador que propone en el intento de explicar el fenómeno que quiere explicar, como una proposición ad hoc, específicamente designada con elementos de su experiencia, para generarla como resultado de su operación, y sin otra necesidad de justificación que ésa" ${ }^{31}$. Y añade, entre irónico y creativo, que metafóricamente es aquí donde reside la poesía del hacer ciencia.

Esto es duro, ya lo sé, pero cada vez parecemos estar más seguros de lo que no son las cosas y menos de lo que son, aunque nos resistimos a tener cierta certidumbre en saber qué es lo que son. Giambattista Vico con su fórmula "verum ipsum factum" en 1710, llegó a defender que la verdad del ser humano

\footnotetext{
${ }^{28}$ Schrödinger, 1958, p. 152.

${ }^{29}$ Schrödinger, 2006, pp. 120-121.

${ }^{30}$ Maturana, 1994, p. 172.

${ }^{31}$ Maturana, 1994, p. 173.
} 
era aquello que el ser humano llega a construir y formar mediante sus acciones. Llegaba al convencimiento de que conocer era un hacer, un generar, un crear, oponiéndose a la idea clásica de que el conocimiento era una actitud pasiva de recepción ${ }^{32}$. En la actualidad, el constructivismo filosófico ${ }^{33}$ intenta separarse del realismo como forma tradicional de conocimiento de la realidad, y para ello se sitúa en un nuevo paradigma, en una nueva forma de relacionar saber y realidad. Mientras la concepción tradicional del conocimiento y las tradicionales teorías cognitivas, consideran que existe una correspondencia casi icónica entre el conocimiento y la realidad responsable de los datos que percibimos, el constructivismo cognoscitivo parte de un principio diferente. El conocimiento no es la computación de una realidad, sino más bien la computación de las descripciones de una realidad. Es decir, las escuelas realistas o anti-realistas cuando tratan de describir una mesa, observan al tocarla, la confirmación de mi sensación visual de que allí hay una mesa, el constructivismo más bien diría que la correlación entre mi percepción táctil y mi impresión visual permite que se genere una experiencia que podría describir diciendo que "aquí hay una mesa".

Y esto presenta un problema y es que las descripciones tienen como límite el lenguaje. Ya Wittgenstein en su proposición 5.6. del Tractatus dice: "Los límites de mi lenguaje significan lo límites de mi mundo" 34 , y esta sería una forma débil de hablar de una cierta "verdad" del escepticismo, ya que como dice un poco más abajo (5.62) "que el mundo es mi mundo se muestra en que los límites del lenguaje (el lenguaje que yo solo entiendo) significan los límites de $m i$ mundo". Desde este punto de vista no hay forma de acabar, a pesar de una larga tradición de argumentos, con el escepticismo, y como dice el propio Wittgenstein, toda tentativa no hace más que reforzarlo. El escepticismo debe ser entendido como una traducción epistemológica de una dificultad real. Tenemos que comprender y luchar contra esa pulsión humana y esa tendencia filosófica de poner en contacto lo que decimos o pensamos con esa gran desconocida: "la realidad".

\footnotetext{
${ }^{32}$ El conocimiento humano estaría condenado a raspar la superficie de la realidad natural, así la verdad humana, de existir, "sería solo una imagen plana, casi una pintura", Mondolfo, 1971, p. 84.

${ }^{33}$ En las dos últimas décadas parece que se ha ido formando cierto consenso en humanidades $y$ en ciencias sociales entorno a la idea de que el conocimiento es algo socialmente construido (concepción unida estrechamente a posiciones progresistas, pos-colonialistas o multiculturalistas), esta tesis no es tan clara en el caso de las ciencias naturales, vid. Borghossian, 2009, p. $16-25$.

${ }^{34}$ Wittgenstein, 1981, p. 163.
} 
Además, los procesos de conocimiento no computan realidades (mesas, galaxias o agujeros negros), sino en todo caso las descripciones de tales entidades. Pero es que además, como cualquier neurofisiólogo nos diría, la computación de una descripción en el plano neuronal (por ejemplo una imagen proyectada en la retina) seguirá siendo elaborada en planos superiores (repetición ilimitada de descripciones) hasta la descripción definitiva, eliminando así un desconocido o desconocida al que hacemos constante referencia como es "la realidad". La "computación recursiva está a la base de todo proceso de conocimiento y de la vida misma" ${ }^{35}$.

Así pues, el aspecto fundamental del conocimiento es su funcionalidad, el conocimiento no se corresponde con la realidad, más bien encaja con ella o no. Ernst von Glasersfeld apunta a la diferencia que en el inglés cotidiano existe entre las palabras match (corresponder, igualar, emparejar) y fit (encajar, ajustar, acomodar), el realista metafísico busca el conocimiento que corresponde con la realidad, mientras que el constructivista busca encajar su teoría con lo que sabemos del mundo. El encaje describe la capacidad de la teoría, pero no del mundo. Cuando decimos de algo que "encaja" (una llave en una cerradura que la abre) ese encaja describe una capacidad de la llave y no dice nada de la cerradura. Desde el punto de vista del constructivismo radical "todos nosotros -hombres de ciencia, filósofos, legos, escolares, animales, seres vivos de todas las especies- estamos frente al mundo circundante como un bandido ante una cerradura que debe abrir (con su manojo de llaves) para adueñarse del botín ${ }^{36}$.

El científico o el ser humano está situado frente al mundo circundante y necesita una teoría que sirva, que encaje (correspondería al término fit de la teoría darwinista o neodarwinista), para adueńarnos de él. El constructivismo rompe con las convenciones y desarrolla una teoría del conocimiento en la cual éste ya no se refiere a una realidad ontológica "objetiva", sino que se refiere a la organización del mundo a través de nuestras experiencias, como concluiría Piaget: "la inteligencia organiza el mundo organizándose a sí misma"37. En este sentido, me gusta del constructivismo su modestia y humildad pues el constructivismo no es una descripción de una realidad absoluta, sino que es

\footnotetext{
${ }^{35}$ Von Foerster, 1988, pp. 44-53.

${ }^{36}$ Von Glasersfeld, 1988, p. 23.

${ }^{37}$ Piaget, 1937, p. 311. La idea tradicional piagetiana de que el niño no sabe disociar correctamente de sí mismo el curso de los acontecimientos o la realidad de las cosas, ni agrupar convenientemente los objetos, si no es de acuerdo con las relaciones que su propia actividad puede introducir (ver Wallon, 1980, p.141), habría que ampliarla al conocimiento científico.
} 
un posible modelo de conocimiento... en el que sobra la supuesta objetividad, como diría Woody Allen, al menos hay una cosa en la que se pierde la objetividad "es imposible vivir la propia muerte con objetividad y, además, cantar una canción" 38 .

${ }^{38}$ Allen, 1974, p. 31. 


\section{Bibliografía}

Allen, W. (1974). Como acabar de una vez por todas con la cultura, Barcelona: Tusquets Editores.

Calvo, T. (1977). "Truth and Dóxa in Parmenides”, Archiv für Geschichte der Philosophie, 59, pp. 245-260.

— (2007). “De Parménides a Gorgias: El mundo verdadero como fábula”, en Sáez, Higuera y Zúniga (eds.), Pensar la nada. Ensayos sobre filosofía y nihilismo, Granada, pp. 159-197.

Calogero, G. (1977). Studi sull'eleatismo, Firenze, n.e.

Von Foerster, H. (1988). “Construyendo una realidad” en Watzlawick, P. (comp.) (1988). La realidad inventada. ¿Cómo sabemos lo que creemos saber?, Buenos Aires: Ed. Gedisa.

Fränkel, H. (1925). “Xenophanesstudien I und II”, Hermes, pp. 174-192.

Von Glasersfeld, E. (1988). “Introducción al constructivismo radical”, en Watzlawick, P. (comp.) (1988). La realidad inventada. ¿Cómo sabemos lo que creemos saber?, Buenos Aires: Ed. Gedisa.

Gigon, O. (1945). Der Ursprung der griechischen Philosophie von Hesiod bis Parmenides, Basel.

Hessen, J. (1970). Teoría del conocimiento, Madrid: Espasa Calpe.

Kant, I. (1984). Prolegómenos, Madrid: Ed. Sarpe.

Maturana, H. (1970). Biology of Cognition (Report 9.0), Illinois, Biological Computer Laboratory.

Maturana, H. (1994). "La ciencia y la vida cotidiana”, en Watzlawick, P. (comp.) (1994). El ojo del observador. Contribuciones al constructivismo, Barcelona: Ed. Gedisa.

Mondolfo, R. (1971). Verum Factum. Desde antes de Vico hasta Marx, Madrid: Siglo veintiuno.

Piaget, J. (1937). La construction du reel chez l'enfant, Neuchâtel, Delachaux et Niestlé.

Putnam, H. (1988). Razón, verdad e historia, Madrid: Ed. Tecnos.

Reinhardt, K. (1985). Parmenides, Frankfurt am Main.

Román, R. (1993). "Meliso de Samos: la corrección de la ontología parmenídea y sus inevitables consecuencias escépticas”, Endoxa. Series Filosóficas, (3), 179-193.

Searle, J. (1995). The Construction of Social Reality, New York: The Free Press. 
Schrödinger, E. (1958). Mind and Matter, Cambridge, Cambridge University Press [version castellana, (1983), Mente y material, Barcelona: Tusquets].

- (2006). La naturaleza y los griegos, prólogo de Víctor Gómez Pin, Barcelona: Tusquets.

Untersteiner, M. (1955). "Il problema del conoscere in Senofane", Sophia, 23, 1, pp. 26-37.

WATZLAWick, P. (1979). ¿Es real la realidad? Confusión-desinformación-comunicación, Barcelona: Ed. Herder.

- (comp.) (1988). La realidad inventada. ¿Cómo sabemos lo que creemos saber?, Buenos Aires: Ed. Gedisa.

- (comp.) (1994). El ojo del observador. Contribuciones al constructivismo, Barcelona: Ed. Gedisa.

Wittgenstein, L. (1981). Tractatus Logico-Philosophicus, Madrid: Alianza Universidad.

Wallon, H. (1980). La evolución psicológica del niño, Barcelona: Ed. Crítica.

Zafiropulos, J. (1950). L’école Éléate, Paris.

Recibido: 20/01/2016

Aceptado: 15/09/2016

Este trabajo se encuentra bajo una licencia de Creative Commons ReconocimientoNoComercial-SinObraDerivada 4.0 Internacional

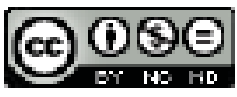


